\title{
Abdominal recto(colpo)pexy for rectal prolapse: is a new era coming?
}

\author{
A. Infantino $\cdot$ A. Lauretta
}

Received: 1 February 2013/Accepted: 11 February 2013/Published online: 16 March 2013

(C) Springer-Verlag Italia 2013

Much water has flown under the bridge since abdominal rectopexy was introduced to treat rectal prolapse but just recently it has regained popularity. Morbidity and risk related to general anesthesia were the major drawbacks making this surgical treatment often unsuitable for more fragile patients. On the other hand, transperineal techniques tend to be associated with less morbidity but a higher recurrence rate. Furthermore, worsening constipation or new onset constipation following abdominal approaches are functional sequelae difficult to prevent and to treat. Indeed postoperative constipation mainly affects functional outcome and is present in up to $52 \%$ of patients [1]. Sigmoid resection associated with rectopexy has been proposed to reduce the risk of postoperative constipation [2] although the risk of anastomotic dehiscence and infection of nonabsorbable implants limit its application. It has been widely demonstrated that the laparoscopic approach is superior to the open approach in terms of morbidity, recovery time, hospitalization [3] and costs [4]. Age no longer seems to be a limit to the laparoscopic abdominal approach: postoperative complications do not differ significantly, and recurrence rates are low in the elderly [5]. It has also been shown that procedures with preservation of the lateral ligaments and limited lateral and posterior rectal dissection, including the "old" Orr-Loygue operation, are associated with good functional outcomes, minimizing postoperative constipation and not increasing recurrence, both in overt rectal prolapse and in rectal intussusception [6]. Since laparoscopic ventral rectopexy (LVR) was introduced by D'Hoore et al. in 2004 [7], several studies have been published

A. Infantino $(\varangle) \cdot$ A. Lauretta

Department of Surgery, Santa Maria dei Battuti Hospital,

Via Savorgnano, 2, 33078 San Vito al Tagliamento, PN, Italy

e-mail: ainfantino@libero.it confirming positive results in terms of constipation and fecal incontinence for both full rectal prolapse and rectoanal intussusception $[5,8,9]$. A limited rectal mobilization is performed only unilaterally reducing the risk of inferior hypogastric nerve injury and therefore leading to a lower incidence of postoperative constipation [7, 9]. Recently, we described a modification of LVR involving mesh fixation to the sacral hollow instead of the sacral promontory with a favorably low risk of postoperative constipation and excellent functional results [10]. Rectocolpopexy perfectly complies both with Petros' "integral theory" about the perineal suspension system [11] and DeLancey's studies on urogenital suspension systems [12]. The frequent association of complete rectal prolapse and rectoanal intussusception with middle compartment prolapse, rectocele and enterocele has been widely documented by both defecography and open magnetic resonance defecography studies $[13,14]$. Tension-free rectal prolapse treatment and simultaneous suspension of the vagina with reinforcement of DeLancey support levels I and II antagonize the forces exerted on the central perineal tendon, addressing middle vaginal compartment disorders. The paper from Maggiori et al. [15], published in this issue, describes LVR results in 33 patients. This prospective study evaluates functional outcome and quality of life over a long period of time: a mean follow-up period of 42 months. The improvements in constipation and fecal incontinence, as well as quality of life, were statistically significant and, above all, they remained stable or even improved over the time. The longterm recurrence rate was favorably low: $6 \%$. One of the main fears and predictable complications was mesh erosion or extrusion through the vaginal or rectal wall. If this is a problem for transperineal approaches, there seems to be virtually no risk of these complications with the abdominal route. 
The question about prosthetic materials is still an open issue. It is still matter of debate whether a biological mesh can ensure long-lasting suspension, less risk of mesh erosion and easier redo-rectopexy in case of failures. Good results have already been published [16] although costs are much higher than for non-biological prostheses, and in absence of comparative studies, we are not able to provide definitive answers to this [17] and other issues, as pointed out by a Cochrane review [18].

Certainly, many problems have been addressed but a lack of prospective comparative studies does not allow us to draw up guidelines. Nevertheless, we can say that a new era has arrived.

Conflict of interest None.

\section{References}

1. Douard R, Frileux P, Brunel M, Attal E, Tiret E, Parc R (2003) Functional results after the Orr-Loygue transabdominal rectopexy for complete rectal prolapse. Dis Colon Rectum 46:1089-1096

2. Laubert T, Kleemann M, Roblick UJ et al (2012) Obstructive defecation syndrome: 19 years of experience with laparoscopic resection rectopexy. Tech Coloproctol. doi:10.1007/s10151-0120925-3

3. Cadeddu F, Sileri P, Grande M, De Luca E, Franceschilli L, Milito G (2012) Focus on abdominal rectopexy for full-thickness rectal prolapse: meta-analysis of literature. Tech Coloproctol 16:37-53

4. Salked G, Bagia M, Solomon M (2004) Economic impact of laparoscopy vs open abdominal surgery. Br J Surg 91:1188-1191

5. Wijffels N, Cunnigham C, Dixon A, Greenslade G, Lindsay I (2011) Laparoscopic anterior rectopexy for external rectal prolapse is safe and effective in the elderly. Does this make perineal approach obsolete? Colorectal Dis 13:561-566

6. Portier G, Iovino F, Lazorthes F (2006) Surgery for rectal prolapse: Orr-Loygue ventral rectopexy with limited dissection prevents postoperative-induced constipation without increasing recurrence. Dis Colon Rectum 49:1136-1140
7. D'Hoore A, Cadoni R, Penninckx F (2004) Long-term outcome of laparoscopic ventral rectopexy for total rectal prolapse. Br J Surg 91:1500-1505

8. D'Hoore A, Penninckx F (2006) Laparoscopic ventral recto(colpo)pexy for rectal prolapse: surgical technique and outcome for 109 patients. Surg Endosc Dec 20:1919-1923

9. Collinson R, Wijffels N, Cunningham C, Lindsey I (2010) Laparoscopic ventral rectopexy for internal rectal prolapse: shortterm functional results. Colorectal Dis 12:97-104

10. Lauretta A, Bellomo RE, Galanti F, Tonizzo CA, Infantino A (2012) Laparoscopic low ventral rectocolpopexy (LLVR) for rectal and rectogenital prolapse: surgical technique and functional results. Tech Coloproctol 16:477-483

11. Petros PE, Swash M (2010) The integral theory: a muscoloelastic theory of pelvic floor function and dysfunction. In: Wieczorek AP, Bartram C (eds) Santoro GA. Pelvic floor disorders. Imaging and multidisciplinary approach to management. Springer, Berlin, pp 17-23

12. Ashton-Miller JA, DeLancey JO (2007) Functional anatomy of the female pelvic floor. Ann N Y Acad Sci 1101:266-296

13. Mellgren A, Bremmer S, Johansson C et al (1994) Defecography. Results of investigations in 2,816 patients. Dis Colon Rectum 37:1133-1141

14. Hausammann R, Steffen T, Wishaupt D, Beutner U, Hetzer FH (2009) Rectocele and intussusception: is there any coherence in symptoms or additional pelvic floor disorders? Tech Coloproctol $13: 17-25$

15. Maggiori L, Bretagnol F, Ferron M, Panis Y (2013) Laparoscopic ventral rectopexy: a prospective long-term evaluation of functional results and quality of life. Tech Coloproct. doi:10.1007/ s10151-013-0973-3

16. Sileri P, Franceschilli L, de Luca E et al (2012) Laparoscopic ventral rectopexy for internal rectal prolapse using biological mesh: postoperative and short-term functional results. J Gastrointest Surg 16:622-628

17. Ahmad M, Sileri P, Franceschilli L, Mercer-Jones M (2012) The role of biologics in pelvic floor surgery. Colorectal Dis 14(Suppl 3): $19-23$

18. Tou S, Brown SR, Malik AI, Nelson RL (2008) Surgery for complete rectal prolapse in adults. Cochrane Database Syst Rev. doi:10.1002/14651858 